\title{
Evolution of microstructure and precipitation in heat-treatable aluminium alloys during ECA pressing and subsequent heat treatment
}

\author{
Nong Gao ${ }^{1, a}$, Marco J. Starink ${ }^{1, b}$, Minoru Furukawa ${ }^{2, c}$, Zenji Horita ${ }^{3, d}$, \\ Cheng $\mathrm{Xu}^{4, \mathrm{e}}$ and Terence G. Langdon ${ }^{4, \mathrm{f}}$ \\ ${ }^{1}$ Materials Research Group, School of Engineering Sciences \\ University of Southampton, Southampton SO17 1BJ, United Kingdom \\ 2 Department of Technology, Fukuoka University of Education, Fukuoka 811-4192, Japan \\ ${ }^{3}$ Department of Materials Science and Engineering, Kyushu University, Fukuoka 812-8581, Japan \\ ${ }^{4}$ Departments of Aerospace \& Mechanical Engineering and Materials Science \\ University of Southern California, Los Angeles, CA 90089-1453, USA \\ an.gao@soton.ac.uk, ${ }^{\mathrm{b}}$ m.j.starink@soton.ac.uk, ${ }^{\mathrm{c}}$ furukawm@fukuoka-edu.ac.jp, \\ dhorita@zaiko.kyushu-u.ac.jp, ${ }^{\mathrm{e}}$ chengxu@usc.edu, ${ }^{\mathrm{f}}$ langdon@usc.edu
}

Keywords: Ageing treatment, aluminium alloys, DSC, equal-channel angular pressing

\begin{abstract}
The precipitation and evolution of microstructure in a spray-cast Al-7034 alloy and a commercial wrought Al-2024 alloy were studied after equal-channel angular pressing (ECAP) using transmission electron microscopy and differential scanning calorimetry (DSC). Microstructural examination showed the grain sizes of both alloys were reduced to the range of $\sim 0.3-0.5 \mu \mathrm{m}$ through ECAP. The DSC analysis identified the occurrence of thermal effects involving the formation, coarsening, dissolution and melting of the precipitate phases and concurrent recrystallization. The heating and ageing response of the alloys processed by ECAP was identified by micro-hardness testing of the samples after interrupted heating and ageing treatments.
\end{abstract}

\section{Introduction}

Equal-channel angular pressing (ECAP) is a severe deformation processing (SPD) procedure in which a sample is subjected to severe plastic deformation by pressing through a die containing a channel bent into an L-shaped configuration [1]. Studies on several ECA processed aluminium alloys have shown that significant grain refinement and superplastic properties may be achieved [2 , 3]. However, the stability of ECAP-deformed materials during continuous heating and the age hardening potential after ECAP has received only limited attention. This issue is important because, even though some truly remarkable properties can be attained with ECAP, achieving strengths in excess of $\sim 600 \mathrm{MPa}$ in Al-based alloys will rely on precipitation strengthening, and generally this will be achieved through appropriate heat treatments after ECA processing. In this study, the as-received and ECA processed Al-7034 and Al-2024 alloys were first investigated using transmission electron microscopy (TEM) and differential scanning calorimetry (DSC) to examine the microstructure and precipitation processes. Subsequently, they were submitted to successive heat treatments to investigate the hardening/softening behaviour through micro-hardness testing under continuous heating ramps and ageing treatments.

\section{Experimental Materials and Procedures}

The experiments were conducted using a spray-cast Al-7034 alloy containing, in wt. \%, 11.5\% Zn, $2.5 \% \mathrm{Mg}, 0.9 \% \mathrm{Cu}$ and $0.2 \% \mathrm{Zr}$, and a commercial wrought Al-2024 alloy containing $4.4 \% \mathrm{Cu}, 1.5$ 
$\% \mathrm{Mg}$ and $0.6 \% \mathrm{Mn}$ with the balance as Al for both alloys. The Al-7034 alloy was produced in the form of an ingot which was extruded into a rod, homogenized at $460^{\circ} \mathrm{C}$ for $16 \mathrm{~h}$ and finally extruded into several bars. The Al-2024 alloy was received both in $\mathrm{T} 351$ condition and as $400^{\circ} \mathrm{C}$ fully-annealed extruded bar [4] but only the annealed condition was processed by ECAP. Repetitive pressings of the same billets were conducted for both alloys up to a maximum of 8 passes. The Al-7034 billets were pressed at $200^{\circ} \mathrm{C}$ and rotated by $90^{\circ}$ in the same direction between consecutive passes in the processing route termed $\mathrm{BC}$ and the Al-2024 billets were pressed at room temperature using route $\mathrm{Bc}-\mathrm{C}$ where they were rotated by $90^{\circ}$ after odd-numbered passes and by $180^{\circ}$ after even-numbered passes. The microstructures were examined using an Hitachi H-8100 transmission electron microscope operating at $200 \mathrm{kV}$. This work was complemented by Electron BackScatter Diffraction (EBSD) and optical microscopy [3]. The DSC experiments were performed using a Perkin-Elmer Pyris 1 in a nitrogen atmosphere at a constant heating rate of $10^{\circ} \mathrm{C} / \mathrm{min}$ [5]. Further details and baseline correction procedures are provided elsewhere $[5,6]$. Samples from both alloys underwent several successive heating ramps with heating rates of $40^{\circ} \mathrm{C} / \mathrm{min}$ up to the maximum temperature of the previous ramp and $10^{\circ} \mathrm{C} / \mathrm{min}$ thereafter, and cooling rates of $50^{\circ} \mathrm{C} / \mathrm{min}$ (see Fig. 1). The peak temperatures of each ramp were in the range of $200-490^{\circ} \mathrm{C}$. After each of the heating ramps, micro-hardness testing was performed after about 10 minutes at room temperature. In each case, the samples were subsequently aged at $100^{\circ} \mathrm{C}$ for 20 hours to assess the age hardening capacity. The micro-hardness was measured again after ageing and the samples were returned to the DSC furnace for the subsequent heating ramp. These experiments were conducted to simulate a solution treatment intermediate anneal by continuous

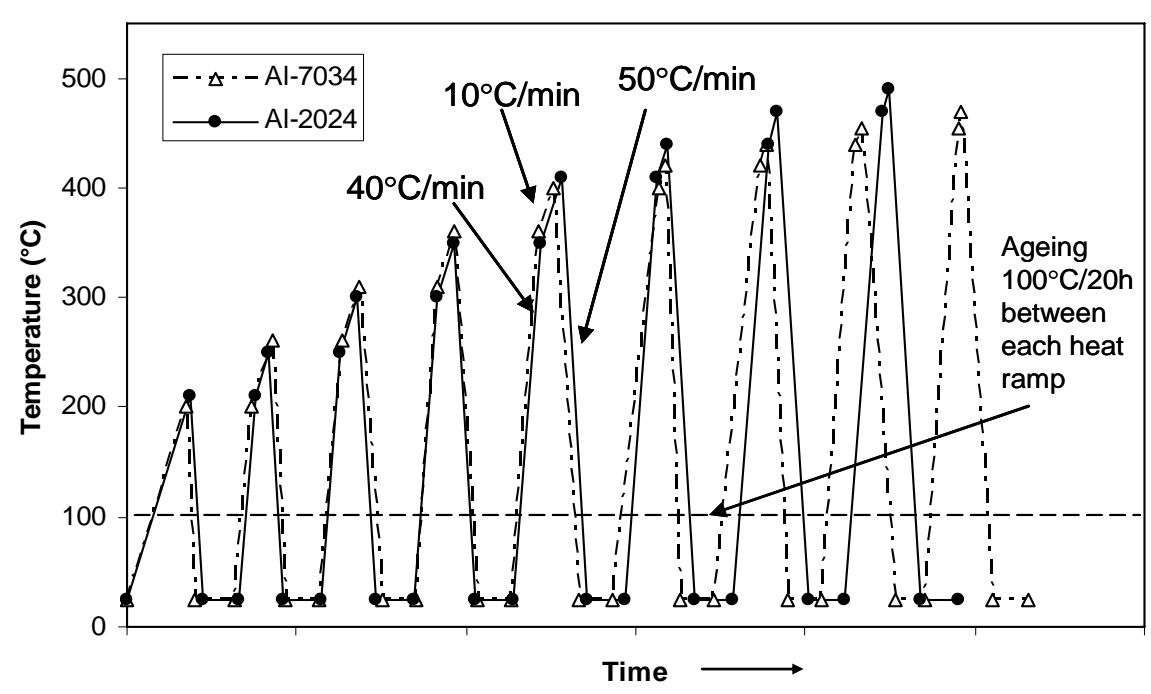
heating at a rate of $10^{\circ} \mathrm{C} / \mathrm{min}$ to temperatures up to the standard solution treatment temperature for the alloys $\left(470^{\circ} \mathrm{C} / 490^{\circ} \mathrm{C}\right)$. The Vickers micro-hardness values, Hv, were obtained from an average of four indentations using a $1 \mathrm{~kg}$ load.

\section{Experimental Results and Discussion}

\section{Microstructural characteristics.}

The as-received Al-7034 alloy contained a fairly equiaxed array of grains with an average grain size of $\sim 2.1 \mu \mathrm{m}$ and there was a low density of dislocations [7]. There are mainly three types of precipitates: large $(>1 \mu \mathrm{m})$, mostly equiaxed $\eta$-phase $\left(\mathrm{MgZn}_{2}\right)$ particles, rod-shaped $\eta$-phase with average lengths and widths of $\sim 0.48$ and $\sim 0.07 \mu \mathrm{m}$ and fine disc-shaped particles representing primarily the metastable hardening $\eta^{\prime}$ phase of the order of $\sim 10 \mathrm{~nm}$. TEM observations after a single pass of ECAP revealed an array of reasonably equiaxed grains with an average size of $\sim 0.5 \mu \mathrm{m}$ and a 
relatively high density of intragranular dislocations. The rod-shaped precipitates in the as-received material were broken up into smaller rod-shaped precipitates, and arrays of fine and reasonably spherical precipitates having sizes in the range of 30-100 $\mathrm{nm}$ were present [7]. The measured grain sizes for 6 or 8 passes of ECAP were slightly smaller than after 1 or 2 passes with average sizes of $\sim 0.3 \mu \mathrm{m}$. In the annealed condition, the Al-2024 alloy contained plate-like grains having approximate dimensions of $\sim 500 \times 300 \times 10 \mu \mathrm{m} 3$ [4]. The matrix contained a dispersion of small particles of 50-100 nm which were identified as the S phase. TEM and EBSD examination of the microstructures after pressing for a total of 8 passes revealed ultrafine and essentially equiaxed grains having average dimensions of $\sim 0.3 \mu \mathrm{m}$.

\section{DSC analysis.}

The DSC curves of the Al-7034 alloy in the as-received condition and after 1, 4 and 8 passes of ECAP have demonstrated the primary thermal effects in $7 \mathrm{xxx}$ alloys $[8,9]$ and these are labelled I to VI in Fig. 2. The major effects in these various regions are interpreted as Guinier-Preston (GP) zone and/or $\eta^{\prime}$-phase dissolution (I), formation of the $\eta$-phase (II), coarsening of the $\eta$ precipitates (III), dissolution of the $\eta$-phase (IV), incipient melting of the T-phase (V) and the onset of full melting of the alloy (VI) [3]. For the as-received material, the dissolution of Guinier-Preston (GP) zones and/or the $\eta^{\prime}$-phase (I) occurs on heating to the ECAP processing temperature of $200^{\circ} \mathrm{C}$ and precipitation of the $\eta$-phase starts when the material approaches the ECAP processing temperature. Coarsening of the $\eta$-phase occurs on continued exposure at the processing temperature and thus on subsequent passes through the ECAP die. In general, these results are consistent with earlier reports of the precipitation reactions occurring in similar alloys $[10,11,12]$. The coarsening reaction designated as (III) involves the coarsening of $\eta$-phase rounded disks or spheres having diameters of $\sim 10 \mathrm{~nm}$, which are different from the larger angular precipitates resulting from fragmentation of the long rod-like $\eta$-phase precipitates present in the as-received alloy. The similarities in the shapes of the DSC curves after 1, 4 and 8 passes demonstrate that the precipitation processes in the Al-7034 alloy are significantly influenced by the precipitate morphology and specifically by the breaking of the rod-like MgZn2 precipitates which

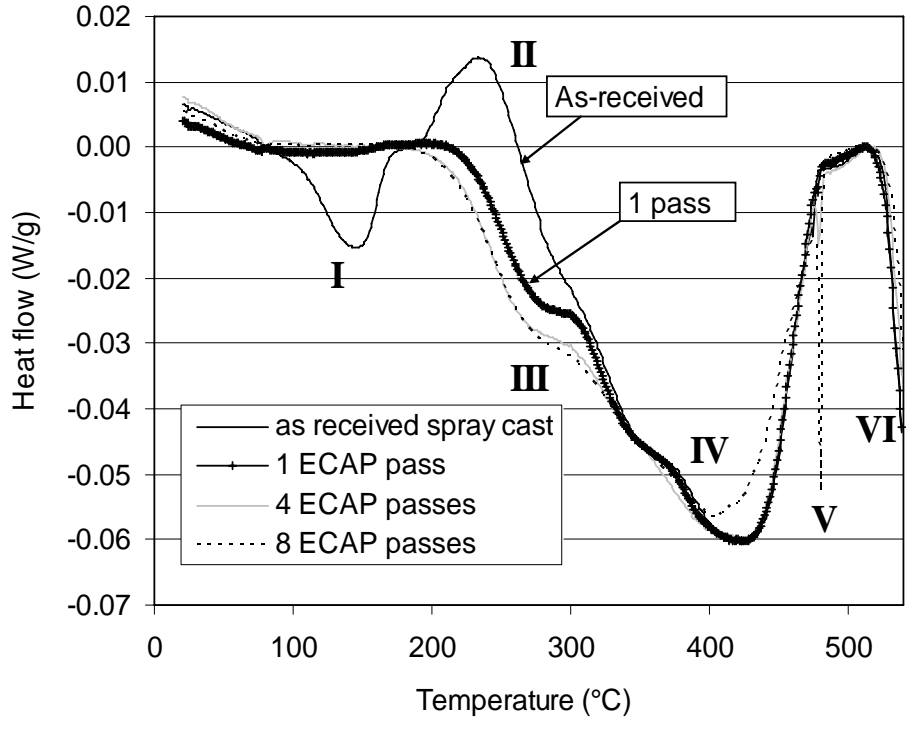

Fig. 2: The DSC curves of Al-7034 alloy. occurs mostly in the first pass of ECAP.

The DSC curves of annealed and ECA processed 2024 samples show many similarities, but they are very different from the DSC curve of the 2024 T351 sample (Fig. 3a). The DSC curve of the T351 material reveals zone/cluster dissolution (I) $\left(160-240^{\circ} \mathrm{C}\right)$ and $\mathrm{S}$ formation in the range of $240-300^{\circ} \mathrm{C}$ with a peak at about $260^{\circ} \mathrm{C}$ (II). S dissolution occurs in the range of $300-500^{\circ} \mathrm{C}$ (IV) [5]. DSC curves for annealed and ECA processed samples do not show zones/clusters dissolution (I) or an $\mathrm{S}$ precipitation peak (II) although they all have a clear S dissolution zone within $300-490^{\circ} \mathrm{C}$ (IV). This indicates that the annealing process at $400^{\circ} \mathrm{C}$ before ECAP leads to a completion of the $\mathrm{S}$ formation. One further interesting observation from the DSC curves is that there are small peaks at about $380^{\circ} \mathrm{C}$ (III) for all ECA processed samples but not for the T351 and annealed samples (Fig. 3b). These peaks move slightly to higher temperature with an increase in the number of ECAP passes, and they occur at 
376,380 and $394^{\circ} \mathrm{C}$ for 2,6 and 8 passes of ECAP, respectively. The heat contents of these exothermic effects decrease slightly at 4,6 and 8 passes by comparison with 2 passes of ECAP. DSC data for an ECA processed Al-5052 alloy also shows an exothermic peak around $350^{\circ} \mathrm{C}$ which was related to recrystallization [13]. It is probable that the peaks around $380^{\circ} \mathrm{C}$ in this 2024 alloy are also due to recrystallization and the marked drop in hardness on annealing above this temperature (see below) further supports this interpretation. The increase in the recrystallization temperature with increasing ECAP passes can be attributed to a refinement of particles such as $\mathrm{Al}_{7} \mathrm{Cu}_{2} \mathrm{Fe}$ and $\mathrm{Al}_{20} \mathrm{Cu}_{2} \mathrm{Mn}_{3}$ [14] which enhances their effectiveness as recrystallization inhibitors. Fig. 3 shows that recrystallization occurs during heating at a temperature where only about a quarter of the $\mathrm{S}$ phase has dissolved. Hence, substantial precipitation hardening in an unrecystallized ECA processed 2024 alloy appears impossible unless a hardened 2024 can be ECA processed at room temperature.

\section{Hardness results during heating ramps and subsequent ageing.}

Nine cycles of heating ramps and subsequent ageing were carried out for the as-received and ECA processed Al-7034 samples ( 1 and 8 passes) using peak temperatures of 200, 260, 310, 360, 400, 420, 440,455 and $470^{\circ} \mathrm{C}$. The $\mathrm{Hv}$ values for the as-received sample show a rapid decrease from 25 to $200^{\circ} \mathrm{C}$ during the heating ramp, with limited further changes after subsequent ramps up to $470^{\circ} \mathrm{C}$ (Fig.
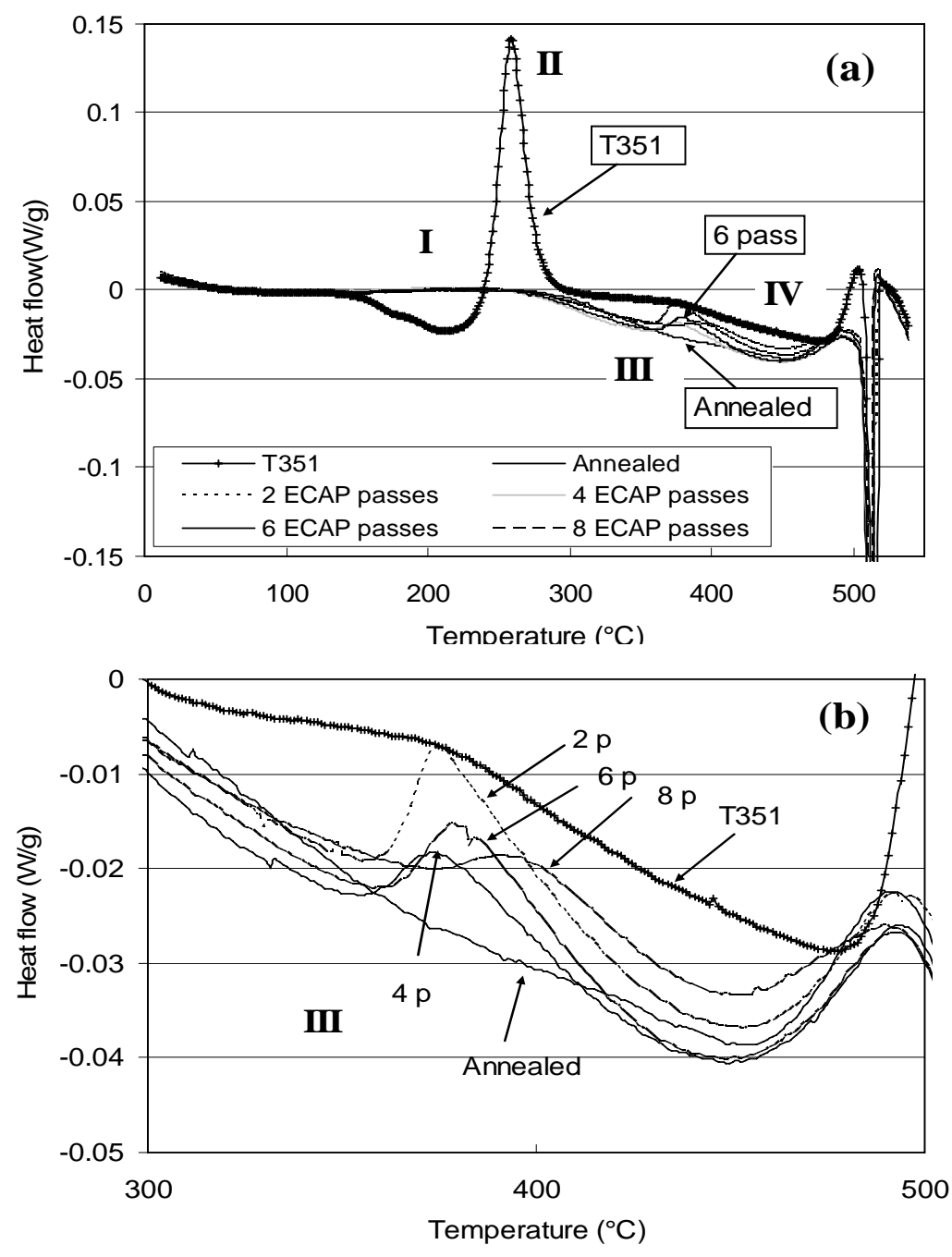

Fig. 3: The DSC curves of Al-2024 alloy: (a) overview and (b) detail between 300 and $500^{\circ} \mathrm{C}$. 4a). The decrease in hardness in the initial stage is due to the reduction in precipitation hardening resulting from the dissolution of some of the fine GP zones and $\eta^{\prime}$-phase which is evident by the DSC curve in Fig. 2 (effect I). The slight increase in hardness on heating to $260^{\circ} \mathrm{C}$ is due to $\eta$ phase formation which is also evident in Fig. 2 (effect II). The hardness achieved by ageing at $100^{\circ} \mathrm{C} / 20 \mathrm{~h}$ after each elevated temperature treatment shows a different trend. The hardness slowly decreases from 200 to $310^{\circ} \mathrm{C}$, then rapidly increases at $360^{\circ} \mathrm{C}$, with a final dramatic increase above $455^{\circ} \mathrm{C}$ to reach a hardness of nearly $200 \mathrm{Hv}$. Within the temperature range of $360-455^{\circ} \mathrm{C}$ the samples show a moderate ageing response, but after heating to $470^{\circ} \mathrm{C}$ the ageing response is very strong. The hardness curves of ECA processed samples are slightly different. The hardness of samples after 1 and 8 ECAP passes is stable until $310^{\circ} \mathrm{C}$ and then slowly decreases until $470^{\circ} \mathrm{C}$. Within the temperature range of $360-455^{\circ} \mathrm{C}$ the samples show a moderate ageing response, but after heating to $470^{\circ} \mathrm{C}$ the ageing response is very strong.

Compared to the as received sample, the ageing response after heating to $360-455^{\circ} \mathrm{C}$ is more limited. The dramatic increase in hardness after heating to $470{ }^{\circ} \mathrm{C}$ and subsequent ageing is also evident for 
the ECA processed samples. Overall, the data in Fig. 4a shows that ECAP has little influence on the hardness achieved after heating to elevated temperatures and subsequent ageing. The initial hardness value of the as-received sample is higher than the ECA processed samples which is in good agreement with yield strength data [7]. This loss of strength is attributed to the use of a pressing temperature of $200^{\circ} \mathrm{C}$ which leads to a dissolution of the hardening $\eta^{\prime}$-phase and a transformation of $\eta^{\prime}$ into $\eta$ with subsequent coarsening [7]. This effectively reduces the number of obstacles available to impede the movement of dislocations. From 200 to $420^{\circ} \mathrm{C}$, the hardness of ECA processed samples is consistently higher than the sample receiving no ECAP treatment. This is probably because the ECA processed samples possess a finer grain size and higher dislocation densities than the as-received

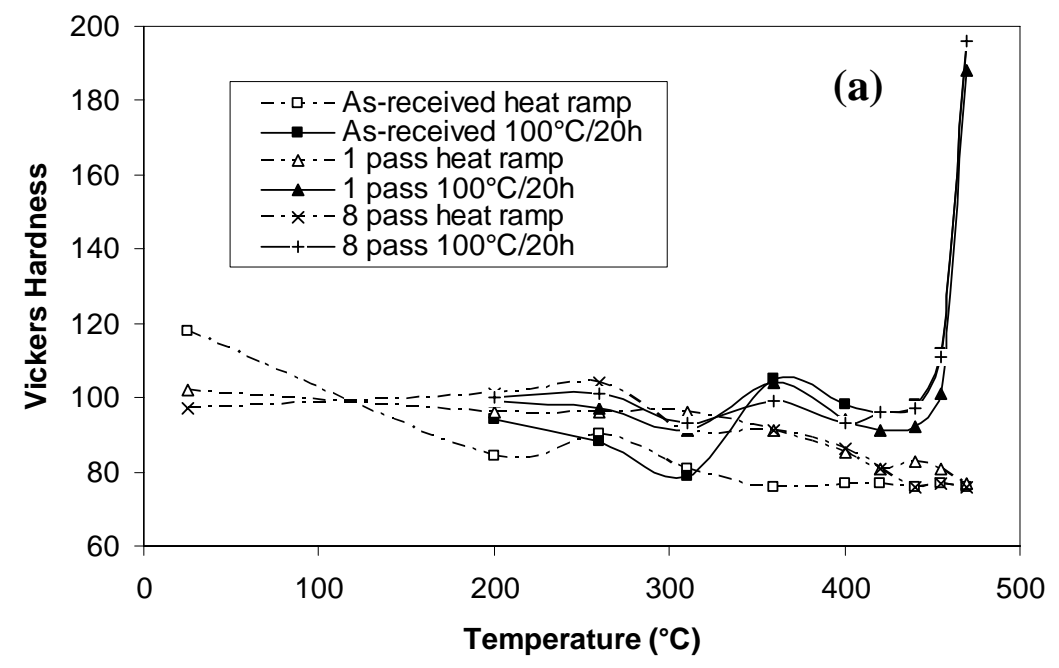

samples, and this difference is retained up to about 350 to $400^{\circ} \mathrm{C}[3,15]$. After heating to $470^{\circ} \mathrm{C}$, subsequent ageing at $100^{\circ} \mathrm{C}$ for 20 hours drastically increases the hardness levels with $\mathrm{Hv}$ values of 192,186 and 195 , respectively, for the as-received, 1 and 8 passes of ECAP samples. This is due to the near complete solutionizing of the $\mathrm{Zn}, \mathrm{Mg}$ and $\mathrm{Cu}$ containing phases such as $\eta$, since this allows extensive precipitation

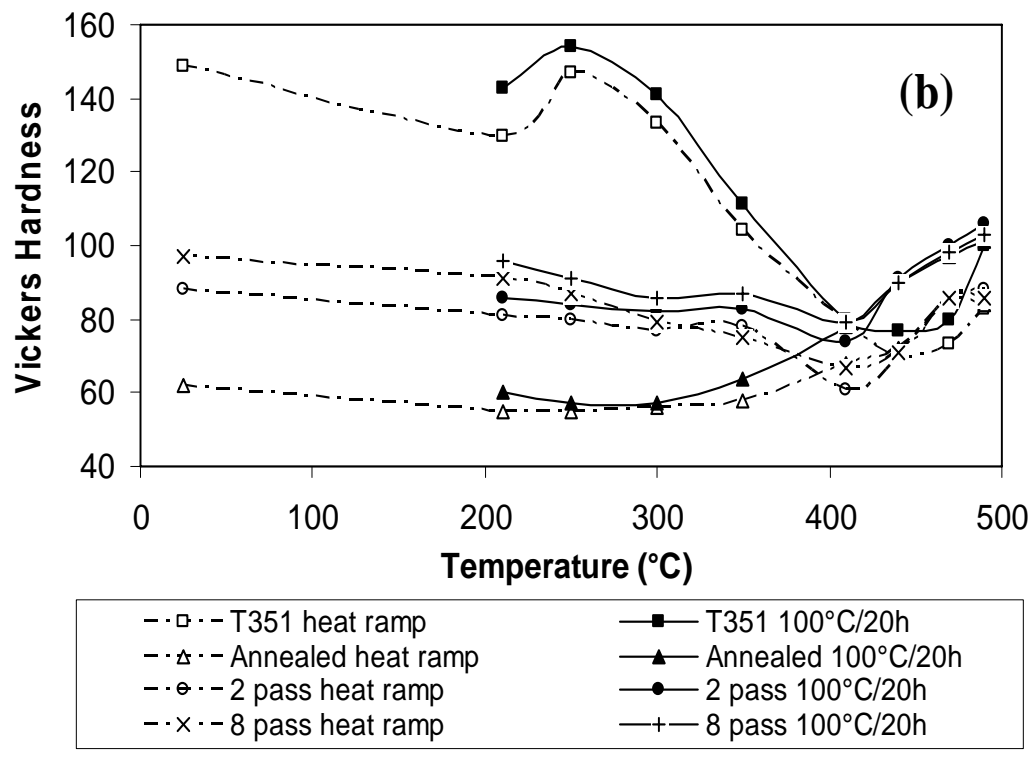

Fig. 4: The hardness values after a heating ramp and ageing for (a) Al-7034 and (b) Al-2024 alloys.

hardening during the subsequent ageing at $100^{\circ} \mathrm{C} / 20 \mathrm{~h}$.

Similar cycles of heating ramps and ageing were also conducted for T351, annealed, 2, 4, 6 and 8 passes of ECAP Al-2024 samples. Here the peak temperatures were chosen as 210, 250, 300, 350, $410,440,470$ and $490^{\circ} \mathrm{C}$. The hardness of the T351 sample first decreases, then increases at $250^{\circ} \mathrm{C}$, and rapidly decreases between 300 and $400^{\circ} \mathrm{C}$ (Fig. 4b). These changes are due to the zone/cluster dissolution, the precipitation of S phase which occurs in the range of 240 to $300^{\circ} \mathrm{C}$ (see Fig. 3a) and the coarsening and dissolution of S precipitates, respectively. The hardness of the annealed and ECAP processed samples is relatively stable on heating to temperatures up to $300^{\circ} \mathrm{C}$. The drop of hardness on heating to $410^{\circ} \mathrm{C}$ is probably due to recrystallization at about $380^{\circ} \mathrm{C}$ which was revealed by the DSC curves in Fig. 3b. The T351 sample shows a higher hardness than the annealed and ECAP condition up to $350^{\circ} \mathrm{C}$. This is reasonable because the original T351 alloy has a microstructure that is conducive to the formation of fine $\mathrm{S}$ phase precipitates on heating to about $250^{\circ} \mathrm{C}$ [16] and this will strengthen the alloy. After an annealing 
treatment at $400^{\circ} \mathrm{C}$, all Al-2024 samples have been severely overaged and recrystallized, resulting in a loss of a significant part of the precipitation and grain boundary strengthening. However, it was demonstrated in earlier work that the strength of the alloy may be restored after ECAP by conducting an appropriate ageing treatment [7]. A comparison of annealed and ECA processed hardness curves indicates that processing by ECAP can introduce a substantial increase of hardness due to a refinement of the grain size and an increase in the dislocation density but this is not sufficient to achieve the strength of the T351 processed material. Heating to temperatures beyond $410^{\circ} \mathrm{C}$ causes an increase in the hardness and an increase in the age hardening capability due to partial solutionizing of the $\mathrm{S}$ phase.

\section{Summary}

An Al-7034 and an Al-2024 alloy were processed by ECAP leading to a reduction of grain size to $\sim 0.3-0.5 \mu \mathrm{m}$. The hardness of the Al-7034 alloy directly after ECAP was lower than in the as-received alloy at room temperature due to the dissolution of the GP zones and the $\eta^{\prime}$-phase during ECAP at $200^{\circ} \mathrm{C}$. After heating to 200 to $310^{\circ} \mathrm{C}$ and subsequent ageing, the hardness of the ECA processed samples was consistently higher than for the as-received sample because the ECA processed samples maintained their finer grains and higher dislocation densities. The ECA processed Al-2024 samples show a higher hardness level than the annealed sample up to $350^{\circ} \mathrm{C}$ due to a refinement in the grain size and an increase in the dislocation density.

\section{Acknowledgements}

This work was funded in part by the Nanomaterials Forum of the University of Southampton and some of the hardness and DSC experiments were performed by Mr N. Le Guen and Mr Y. Muller. The work was also partially supported by the National Science Foundation of the United States under Grant No. DMR-0243331.

\section{References}

[1] M. Furukawa, Z. Horita, M. Nemoto and T.G. Langdon, J. Mater. Sci. Vol. 36 (2001), p. 2835.

[2] C. Xu, M.Furukawa, Z. Horita and T.G. Langdon, Adv. Eng. Mater. Vol. 5 (2003), p. 359.

[3] M. J. Starink, N. Gao, M. Furukawa, Z.Horita, C. Xu and T.G. Langdon, Rev. Adv. Mater. Sci. Vol. 7 (2004), p. 1.

[4] S. Lee, M. Furukawa, Z. Horita and T.G. Langdon, Mater. Sci. Eng. Vol. A342 (2003), p. 294.

[5] N. Gao, L. Davin, S. Wang, A. Cerezo and M.J. Starink, Mater. Sci. Forum Vol. 395-402 (2002), p. 923.

[6] M.J. Starink, Int. Mater. Rev. 49 (2004) 191-226.

[7] C. Xu, M.Furukawa, Z. Horita and T.G. Langdon, Acta Mater. Vol. 57 (2005), p. 749.

[8] M.J. Starink and X.M. Li, Metall. Mater. Trans. Vol. A34 (2003), p. 899.

[9] M.J. Starink and S.C. Wang, Acta Mater. Vol. 51 (2003), p. 5131.

[10] R.M. Allen and J.B. Vande Sande, Acta Metall. Vol. 28 (1980), p. 1185.

[11] K. Stiller, P.J. Warren, V. Hansen, J. Angenete and J. Gjønnes, Mater. Sci. Eng. Vol. A270 (1999), p. 55.

[12] V. Hansen, O.B. Karlsen, Y. Langsrud and J. Gjønnes, Mater. Sci. Tech. Vol. 20 (2004), p. 185.

[13] T.L. Tsai, P.L. Sun, P.W. Kao and C.P. Chang, Mater. Sci. Eng. Vol. A342 (2003), p. 144.

[14] S.C. Wang and M.J. Starink, Int. Mater. Rev. (2005), in press.

[15] C. Xu, M. Furukawa, Z. Horita and T.G. Langdon, Acta Mater. Vol. 51 (2003), p. 6139.

[16] M. J. Starink, N. Gao and J. L. Yan, Mater. Sci. Eng. Vol. A387-389 (2004), p. 222. 